\title{
Does Crowdsourcing as Part of User-Driven Innovation Activity Affect Its Results? An Empirical Analysis of R\&D Departments in Poland
}

\author{
Katarzyna Szopik-Depczyńska ${ }^{1, *(1)}$, Izabela Dembińska ${ }^{2}$, Agnieszka Barczak ${ }^{3}{ }^{(D)}$, \\ Angelika Kędzierska-Szczepaniak ${ }^{4}$, Krzysztof Szczepaniak ${ }^{4}{ }^{\oplus}$, Radosław Depczyński ${ }^{5}$ and Giuseppe Ioppolo ${ }^{6}$
}

check for updates

Citation: Szopik-Depczyńska, K.;

Dembińska, I.; Barczak, A.;

Kędzierska-Szczepaniak, A.;

Szczepaniak, K.; Depczyński, R.;

Ioppolo, G. Does Crowdsourcing as

Part of User-Driven Innovation

Activity Affect Its Results? An

Empirical Analysis of R\&D

Departments in Poland. Energies 2021,

14, 5809. https://doi.org/10.3390/

en14185809

Academic Editors: Sergey Zhironkin and Krushna Mahapatra

Received: 8 July 2021

Accepted: 8 September 2021

Published: 14 September 2021

Publisher's Note: MDPI stays neutral with regard to jurisdictional claims in published maps and institutional affiliations.

Copyright: (c) 2021 by the authors. Licensee MDPI, Basel, Switzerland. This article is an open access article distributed under the terms and conditions of the Creative Commons Attribution (CC BY) license (https:// creativecommons.org/licenses/by/ $4.0 /)$.
1 Faculty of Economics, Finance and Management, Institute of Management, University of Szczecin, Cukrowa 8, 71-004 Szczecin, Poland

2 Faculty of Economics and Engineering of Transport, Maritime University of Szczecin, ul. Pobożnego 11, 70-507 Szczecin, Poland; i.dembinska@am.szczecin.pl

3 Faculty of Economics, West Pomeranian University of Technology in Szczecin, ul. Janickiego 31, 71-270 Szczecin, Poland; agnieszka-barczak@zut.edu.pl

4 Faculty of Management, University of Gdansk, ul. Armii Krajowej 101, 82-814 Sopot, Poland; a.szczepaniak@ug.edu.pl (A.K.-S.); krzysztof.szczepaniak@ug.edu.pl (K.S.)

5 Doctoral School, Institute of Management, University of Szczecin, Cukrowa 8, 71-004 Szczecin, Poland; radoslaw.depczynski@phd.usz.edu.pl

6 Department of Economics, University of Messina, Via dei Verdi 75, 98122 Messina, Italy; giuseppe.ioppolo@unime.it

* Correspondence: katarzyna.szopik-depczynska@usz.edu.pl

\begin{abstract}
Entrepreneurs have long been convinced about the power and possibilities of the Internet. Nowadays, the Internet is an integral tool for the functioning of a company, not only as an alternative distribution channel, but also as a channel of information and communication flow, a means of interaction with the environment. The increasing use of the Internet, and especially of social media, made it possible to escalate the activity of various social groups in various areas of the company's activity, including innovation, leading to the development of crowdsourcing. Crowdsourcing has redefined the existing production rules and ways of using labor resources. Its potential lies in openness, partnership, resource sharing and global action. There are already many studies on crowdsourcing and innovation, but little attention is paid to the relationship between crowdsourcing and the determinants of innovation activity. Thus, the aim of this research is examining whether the use of crowdsourcing while cooperating with product users in accordance with the concept of user-driven innovation (UDI) has an impact on selected aspects of innovative activity. An original questionnaire was used for the study. Fifty-seven R\&D departments in Poland participated in the research. For the purpose of the analysis, the Kendall and V-Cramer tau correlation coefficient was used. These methods are complemented by the Ward agglomeration method. The research results show a cooperation with consumer results in the development of innovative activities in the studied R\&D departments of enterprises in Poland. Using crowdsourcing results in the introduction of more product innovations, the introduction of new or significantly improved technological processes, as well as the implementation of a greater number of research and development projects.
\end{abstract}

Keywords: crowdsourcing; innovation; user-driven innovation; management; social media

\section{Introduction}

The term crowdsourcing was used by Jeff Howe to describe the use of various people's knowledge and experience [1]. He explained that crowdsourcing is, in a way, the outsourcing of any broadly defined activity of a company to an unspecified, broad group of Internet users in the form of an open invitation. It consists in asking a wide range of people for a solution, suggestion, or opinion regarding a product or initiative. Notably, the people 
to whom the inquiry is addressed do not have to be (and most often are not) employees of a specific company or experts in a specific field. The definition introduced by Howe suggests that crowdsourcing was born as an alternative to outsourcing. Undoubtedly, the development of crowdsourcing has become possible thanks to the development of social media. Internet users are happy to share their ideas, support, suggest, and even allow their ideas or photos to be published. It is the suggestions and solutions proposed by Internet users, the participants of various forums, and social media that often enable the implementation of specific goals set by the organizer/author of a question or problem (an enterprise, an organization, a government, a community). Thanks to the Internet, crowdsourcing enables the access to a virtually unlimited number of people and the creativity and the fresh perspective of potential advisors.

The aim of our research was to determine the relationship between crowdsourcing and selected elements of innovative activity in R\&D departments of enterprises. The survey was conducted in a group of 57 companies in Poland. The necessary condition for participation in the study was a declaration of the availability of R\&D facilities (department, unit) and cooperation with users as part of user-driven innovation activity in R\&D departments. It should be emphasized that these are pioneering studies, both in Poland and internationally, which focused on the analysis of the cooperation with users from various sectors of the economy and, more importantly, on the analysis of the connections between crowdsourcing and the R\&D departments of enterprises. This pioneering nature of the research has become the fundamental rationale behind the selection of this problem. It was noticed that crowdsourcing as a tool for innovation and R\&D activities is still little researched and that the conclusions from empirical research are used to enrich and develop theories in this area.

To achieve the aim of the research, a literature review was first performed. Two research questions were formulated: (1) how is the relationship between crowdsourcing and the innovation process described in the literature? (2) What is the impact of crowdsourcing on the specific attributes of the innovation activity of enterprises, specifically R\&D departments, and what are the leading directions of research in this area? The literature review allowed for the conceptualization of empirical research. The aim of the research is examining whether the use of crowdsourcing while cooperating with product users in accordance with the concept of user-driven innovation (UDI) has an impact on selected aspects of innovative activity. It was based on the assumption that crowdsourcing used in cooperation with product users in accordance with the concept of user-driven innovation affects the results obtained in innovation activities in research and development departments (units/sections) of enterprises in Poland. The main hypothesis is that the usage of crowdsourcing within the user-driven innovation concept affects the number of product and process innovations implemented by the studied companies. For the purpose of the analysis, the Kendall and V-Cramer tau correlation coefficient was used. These methods are complemented by the Ward agglomeration method. The results of the research allowed us to formulate conclusions of a theoretical and practical nature. This research logic determined the structure of the article.

\section{Literature Review}

One of the most important methods of implementing innovations aimed at creating new ideas and solutions based on the knowledge and needs of consumers is the approach called User-Driven Innovation (UDI). The UDI concept is based on a better understanding and recognition of the explicit and implicit needs and preferences of consumers. This is done by creating effective mechanisms for obtaining and using information from consumers, and very often by using their ideas and ready-made solutions. The development of the UDI concept is a consequence of evolution models and systems for understanding innovation [2-5].

When using the concept of user-driven innovation in enterprises, the basis for gaining knowledge is its exchange, and the main goal of taking action is to accelerate the innovative 
process. This concept is gaining importance with the development of Web 2.0 technology. The tasks carried out under the UDI concept can be supported by social networks, which are currently treated as a new business model, allowing entrepreneurs from various sectors to connect with the scientific community (scientists, researchers, inventors) and the creative consumer community. Created platforms, such as NineSigma.com, Innocentive.com, innopena.pl, or Innowacyjnamedycyna.pl (all accessed on 12 May 2021), are often the result of projects financed by the European Union. In this business model, the platforms include bidders (enterprises and institutions looking for solutions to problems), prosumers (users proposing solutions), and platform administrators (supporting prosumers' contact with bidders). The users are individuals and enterprises, supporting independent consultants and research centers [6]. Virtual communities, on the other hand, are groups of people who communicate via the Internet. Many different platforms are used for this purpose (blogs, videoblogs, microblogs, social media), which allows the creation of a prosumer community as an environment for knowledge transfer [7]. An important tool is crowdsourcing, as one of the main ways to create user innovation in the modern world. Thanks to it, the organization delegates its tasks to an open, specialized, large group of people, treating it as a tool for engaging users in the innovation process. The company does not employ specialists, but through internet platforms it communicates with a wide group of recipients. In this way, it gains many different solutions and specific ideas. The best projects are put into practice [8]. An example of such a platform in Poland is Sprinet.pl, where specific tasks to be solved are sent to an unidentified group of people (invitation open using Web 2.0 tools) [9].

The theoretical basis of the term crowdsourcing, although becoming more and more rich, is still unstable and disordered. There are many definitions that emphasize various aspects of crowdsourcing, showing research pluralism in this field. However, it is difficult to find a leading universally accepted definition. Nevertheless, thanks to new practical experiences, the perception of crowdsourcing is constantly evolving, even though this evolution appears unstructured. It should be noted that Howe's aforementioned definition is the one most often referred to. However, it has some limitations. An interesting, extensive review of the definition of crowdsourcing was carried out by Estellés-Arolas and González-Ladrón-de-Guevara [10]. On the basis of 40 definitions, they found that there are three elements differentiating the understanding of the concept of crowdsourcing-crowd, initiator, and process. They noticed that there were two characteristics of the crowd: the number of people and their typology. With regard to the person who initiates crowdsourcing processes (crowdsourcer), the company is most often identified, directly or indirectly. Regarding the type of process at which crowdsourcing is addressed, Estellés-Arolas and González-Ladrón-de-Guevara conclude that it is most often perceived as outsourcing, problem solving, online distributed process, work organization, online distributed production model, an open innovation process, or a business or strategic model. The analysis of these elements allowed for the generation of the following definition [10]: "crowdsourcing is a type of participative online activity in which an individual, an institution, a non-profit organization, or a company proposes to a group of individuals of varying knowledge, heterogeneity, and number, via a flexible open call, the voluntary undertaking of a task, bringing their work, money, knowledge and/or experience, which always entails a mutual benefit". We believe that this definition represents the essence of crowdsourcing, emphasizing the integral elements of crowdsourcing indicated above. Thus, it bears the hallmarks of universalism. That is why we adopted it as the basic definition for our research.

Crowdsourcing is described as a tool/source of innovation used in innovation projects $[11,12]$. It provides a chance for Internet users to give an opinion on a product at an early stage of its development, which enables the quick detection of errors and possible discrepancies between the expectations of potential customers and the product that a company has designed. There are different ways to reach customers and use crowdsourcing. One of the most frequently used solutions is the competition formula. It consists in announcing a competition among customers, students, and even employees regarding 
specific solutions (product improvement, a new offer, brand refreshment or logo, etc.). The best ideas, that the company decides to use, are most often awarded a prize (the prize may or may not have an economic dimension). The use of crowdsourcing may also be possible through orders directed to the labor market, the contact with communities of creators of complementary offers (complementators), and the cooperation with creative communities (collaborative communities) [13].

In crowdsourcing, preparation is also vital. Brabham [14] listed four main elements that are crucial for the proper functioning of crowdsourcing: organization, community, environment (social media or platforms that enable the interaction between society and business), and mutual benefits for the community and the enterprise. If any of these elements is missing, the term crowdsourcing loses its full meaning. These mutual benefits and the interaction between the actors involved in crowdsourcing are crucial for the success of the entire process. Support or feedback must be provided voluntarily by those who actually want to participate in such activities. Thanks to the cooperation based on the crowdsourcing formula, participants should be able to satisfy their needs-these may be the needs of recognition or improvement of skills, but in some cases they may have a financial dimension (e.g., cash prizes in organized competitions).

There is a lot of information and research in the literature showing that crowdsourcing contributes to innovation growth in organizations [15]. In addition, it gives a chance to get to know the opinion about the product practically before its creation or at an early stage of development, which in turn allows for the detection of errors very early and the introduction of corrections in manufactured products, so that the result is consistent with customers' expectations. Thanks to the cooperation and interaction with customers, enterprises have a chance to increase their innovativeness [16,17].

Crowdsourcing is used increasingly often by enterprises, local government units, and local government organizations worldwide. These entities noticed the potential of crowdsourcing, which translates into their innovativeness. However, it is important that crowdsourcing be a well-planned and thoughtful process. Therefore, it is legitimate to examine whether and to what extent crowdsourcing is used in enterprises in their innovative activities, especially in research and development.

Crowdsourcing is successfully used in many industries, practically in every area of activity: in various complex problems of enterprises [18,19], in logistics [20,21], in services [22], and particularly in tourism [23,24], but also in meteorological systems [25] or in the wine industry [26]. Crowdsourcing is also increasingly used in innovations in the pharmaceutical industry. Thompson and Bentzien [27] presented the current state of innovation in pharmaceutical companies and crowdsourcing in drug discovery. It is an ideal solution, treated as a new approach to a radically changing consumer profile.

Enterprises are interested in researching social media because they see it as an opportunity to improve the path from innovation to commercialization. The development of social media forced a change in the communication with customers. Enterprises have become more open to suggestions from customers, who, in turn, are willing to engage in the development processes of their favorite products [28].

Crowdsourcing based on electronic platform operation principles may constitute a virtual space for developing creativity, ingenuity, and enterprise innovation [29]. After 2020, even more than before due to the prevailing pandemic, entrepreneurs realized that remote cooperation is possible and effective. Such observations may contribute to another increase in the importance of crowdsourcing in the development of enterprises. Moreover, if companies want to remain competitive, they must try to use their customers' knowledge. It is crowdsourcing that gives the opportunity to actively participate in innovation processes [30].

Crowdsourcing can also be treated as a way by which external information has a chance to reach the company's decision-making systems and, in particular, the systems related to innovation [31]. Online social networks, which share ideas, drive innovation in enterprises. This phenomenon has become the subject of much scientific research, e.g., 
examining the importance of social networks in promoting organizations' development and indicating that crowdsourcing contributes to innovation development [32]. It can become an excellent opportunity for enterprises to support and undertake innovative solutions in the field of R\&D. The interaction between the social environment and entrepreneurs can bring many positive effects not only for the company but also for society. These benefits result primarily from the use of the so-called collective intelligence [33].

Although knowledge about crowdsourcing is gradually increasing, a complete understanding of the problem solving process of outsourced innovative initiatives is still lacking. Important discoveries in this area were brought by the research of Natalicchio et al. [34], which found that there are interactions between the characteristics of innovation problems, solution developers (problem solvers) and crowdsourcing platforms, and problem solving outcomes. Ghezzi et al. [35] highlight other issues as well. First, they believe that one of the main problems in crowdsourcing is to define the structure of innovation problems to be reported to the group of solvers. Second, they argue that innovation problems often need to be overhauled, especially when they are particularly complex, for example by breaking them down into modular, stand-alone problems, which facilitates the crowd. Third, seekers must ensure that the problem of innovation is clearly understood by providing solvers with sufficient information while avoiding the limitations of their creativity. In conclusion, Ghezzi et al. indicate that the structure of an innovative problem determines its solvability, its comprehensibility, and the participation of solvers in the crowdsourcing session.

Jespersen [36] examined how design decisions relate to the outcome of an innovation system. She showed that the optimal crowdsourcing project that addresses the innovation system depends on the target innovation environment. Scientists indicate that R\&D opportunities from inside the enterprise are significant for innovation results; however, combining them with external resources has long been considered beneficial for enterprises innovative development [37]. The innovativeness of enterprises and their involvement in $R \& D$ is also connected with the development and innovation of cities, which can be treated as an innovation and entrepreneurship driving force, which translates into the improvement of citizens' quality of life as well as local economic growth [38].

The proper formulation of the crowdsourced problem is one thing. Another important issue regards the kind of situation in which it is worth reaching out to the crowd, i.e., for which problems. Crowdsourcing may be more or less effective depending on the specific area of application of the problem [35]. For example, Poetz and Schreier [39] found that crowd-driven solutions are valuable in the earlier idea generation phase.

An essential factor that should be taken into account is the motivation of potential task participants. They may choose to participate in certain activities for a variety of reasons. The motivating factors can be divided into internal (fun, challenge) and external (publicity, financial motive). Research on the classification and significance of these factors was conducted by Zheng et al. [40] and Oguz [41]. It was indicated that different motivation types were related to the accuracy of the generated solutions in different ways. Researchers also examined the factors that determine the success of specific crowdfunding platforms [42].

Zhao [43] suggests looking at crowdsourcing platforms from a $4 \mathrm{P}$ perspective: phenomenon, platform, profits, and prospects. The first $\mathrm{P}$-Phenomenon-is referred to as user empowerment and collective intelligence (shared intelligence). The second P-Platform-is interpreted in terms of the following elements: competitive climate, gamification, cocreation experience, user roles. In terms of the third P, Zhao [43] proposes the investigation of crowdsourcing platforms in terms of the effect, seen as creative performance, brand loyalty, and knowledge creation. In the end, the prospects present a potential evolution of the idea crowdsourcing platforms with two perspectives: mobile crowdsourcing and crowdsourcing commerce.

In recent years, due to the increased role of customers in the process of adapting products to their requirements and expectations, it has become particularly important to define the scope of relationships between enterprises and product users and their nature. The literature on the subject shows that so far no comprehensive research has been 
conducted to define the conditions for the use of crowdsourcing in R\&D departments of enterprises and their innovation activity. Thus, the present analysis is new and provides novel insights into the current state of research. The analysis of the literature shows that research on the use of crowdsourcing in innovative activities of enterprises is justified because there are research gaps. Our research tries to fill these gaps.

\section{Methodology}

\subsection{Description of the Research Sample-Basic Information}

The analysis of answers to the main questions concerning the characteristics of the phenomenon of using crowdsourcing in R\&D activities in the surveyed enterprises provided many interesting results, which are presented in this article. It should be emphasized that this is the first research conducted both in Poland and abroad that focused on the use of the UDI concept in various sectors of the economy, and, more importantly, related to the connection of the use of the user-driven innovation concept in the R\&D departments of enterprises. The research was quantitative and qualitative. In the case of the main part of the characteristics of the use of crowdsourcing, it was possible to verify the results of the research enriched with an in-depth statistical analysis. However, this was not possible to the same extent in all cases. Explanatory analyses (concerning the influence of variables) and exploratory analyses (characterizing a given phenomenon) were carried out.

An original questionnaire was used for the study. Companies that use UDI were selected, taking into account the age of the enterprise and the Polish Classification of Activities codes. A full survey was planned for a sample of 137 companies in Poland, conducted using the technique of telephone interviews, and 57 companies agreed to participate. Thus, the response rate was $41.6 \%$ of the general population units. Due to the selection of the sample, it was therefore a comprehensive study-the request to participate in the study was addressed to all identified enterprises using UDI in their R\&D departments.

The results of the study conducted with the participation of $41.6 \%$ units of a given population reflect the structure of the general population, as the properties of this part of the population are similar or the same as those of the general population.

In addition to the case study method, many statistical methods were used in this work, which made it possible to perform analyses after the survey and to verify the research hypotheses. The selection of statistical methods was limited by the type of variables and properties of the studied sample. The survey was carried out using a structured interview method-by phone, according to a previously prepared scenario, based on the proprietary questionnaire. The answers were coded in accordance with the adopted rules in the form of a questionnaire. After coding the questions and entering the questionnaires into the database, a data analysis was performed using Excel and Statistica 13.0. The variables (except for the year of establishment of the enterprise) were of an ordinal or nominal character. In the course of the analysis, it turned out that the distributions of ordinal variables did not meet the normality criterion. The nature of the variables and their distributions implied limitations in the application of parametric methods.

Most of the analyses are based on descriptive statistics. Considering that the study covered over $40 \%$ of the general population and the innovative nature of the work, and thus the inability to refer to the results obtained by other researchers, a detailed description and the characteristics of the population of enterprises in Poland implementing UDI systems, according to quantitative and qualitative criteria, can be seen in the form of an extended case study.

\subsection{Methods}

In order to generalize from a random sample and avoid sampling errors or biases, a random sample needs to have an adequate size [44]. It is possible to use several formulas to determine such a sample, but for the purposes of the study, the following formula was selected: 


$$
n=\frac{p(100-p) z^{2}}{e^{2}}
$$

where:

$n$-the required sample size,

$p$-the percentage of occurrence of a state or condition,

$e$ - the maximum percentage error required,

$z$ - the value corresponding to the level of confidence required.

Adjusting the size of the research sample to the population's size opens the possibility of generalizing the results obtained from the sample to all entities.

The first stage of the analysis is to determine the value of the correlation coefficients in the sample. Tau Kendall's correlation coefficients are used to assess the strength of the relationship between the variables measured on an ordinal scale or whose values were ranked. This ratio is computed based on the differences in the probabilities of event A (two variables are in the same order within the observed data) and event $B$ (the order of the variables differs). Two variants are calculated: $t a u-b$ and $t a u-c$. They differ in how they treat tied ranks, i.e., how they rank the same values [45].

Kendall's coefficient of correlation can also be interpreted as a standard coefficient of correlation computed between two sets of $n(n-1)$ binary values, where each set represents all the possible pairs obtained from $\mathrm{N}$ objects and assigning a value of 1 when a pair is present in the order, and 0 if not [46].

Two formulas for the Kendall tau correlation coefficient can be found in the literature:

1. for data that have been ranked:

$$
\begin{gathered}
\tau_{b}=\frac{P-Q}{\sqrt{\left(P+Q+T_{X}\right)\left(P+Q+T_{Y}\right)}} \\
\tau_{b} \in\langle-1,1\rangle
\end{gathered}
$$

2. for tables with any number of rows and columns:

$$
\tau_{c}=\frac{2 m(P-Q)}{n^{2}(m-1)}
$$

where:

$P$-the number of concordant pairs whose ranks drift in the same direction,

$Q$ - the number of pairs whose ranks drift in opposite directions.

It should be noted that the coefficients $\tau_{b}($ tau- $b)$ and $\tau_{c}($ tau-c) do not differ much in value if the data matrix's marginal values are approximately equal to the count [45].

After determining the correlation coefficients, it is necessary to test their statistical significance. For $n \geq 10$, one can test the null hypothesis by converting $\tau$ to the value of $\mathrm{Z}$ as:

$$
Z_{\tau}=\frac{\tau}{\sigma_{\tau}}=\frac{\tau}{\sqrt{\frac{2(2 n+5)}{9 n(n-1)}}}
$$

The $\mathrm{Z}$ value is normally distributed with a mean of 0 and a standard deviation of 1 [43].

In the test, the hypothesis $H_{0}: \rho=0$ is rejected in the following cases [42]:

$z \geq z_{\alpha / 2}$ (two-sided test),

$z \geq z_{\alpha}$ (right-sided test),

$z \leq-z_{\alpha}$ (left-sided test).

where $\rho$-correlation coefficient in the general population.

In addition to the Kendall tau correlation coefficient, the analysis also used the VCramer correlation coefficient. The V-Cramer correlation coefficient is a measure that is based on the dependency statistics $\chi^{2}$. It is determined from the following formula [47]: 


$$
V=\sqrt{\frac{\frac{\chi^{2}}{N}}{\min (r-1, c-1)}}
$$

where:

$\mathrm{N}$-total number of observations classified in the contingency table,

$r$-number of rows in the contingency table,

$c$ - the number of columns in the contingency table.

The V-Cramer correlation coefficient takes values from the range $\langle 0,1\rangle$, where $\mathrm{V}=0$ means independence, and $V=1$ is the perfect relationship between the variables.

The J. Guilford's classification was used to interpret the obtained results, according to which $[14,26,48]$ :

$|r|=0$-lack of correlation

$0.0<|r| \leq 0.1$ - dim correlation

$0.1<|r| \leq 0.3$-weak correlation

$0.3<|r| \leq 0.5$-average correlation

$0.5<|r| \leq 0.7$-high correlation

$0.7<|r| \leq 0.9$ - very high correlation

$0.9<|r|<1.0$-almost full correlation

$|r|=1$-full correlation.

The confidence interval can be defined as follows: let the feature $\mathrm{x}$ have a distribution in the population with an unknown parameter $\theta$. A random sample of $x_{1}, x_{2}, \ldots, x_{n}$ should be selected from the population. A confidence interval $\left(\theta_{1}, \theta_{2}\right)$ with a confidence level of $1-\alpha$ is the interval that meets the condition:

$$
P\left(\theta_{1}<\theta<\theta_{2}\right)=1-\alpha
$$

where $\theta_{1}, \theta_{2}$-functions determined based on a random sample.

The determined correlation coefficients were used to build the confidence intervals for the correlation coefficient, indicating the range in which the value of the correlation coefficient for the entire population falls within a certain probability. This range is determined according to the following formula (for a large sample):

$$
P\left(-z_{\alpha}<\frac{r-\rho}{1-r^{2}} \sqrt{n}<z_{\alpha}\right)=1-\alpha
$$

and after transforming, we get the formula:

$$
P\left(r-z_{\alpha} \frac{1-r^{2}}{\sqrt{n}}<\rho<r+z_{\alpha} \frac{1-r^{2}}{\sqrt{n}}\right)=1-\alpha
$$

where:

$\rho$-correlation coefficient in the general population

$z_{\alpha}$-the value from normal distribution tables so that the equality holds: $P\left(-z_{\alpha}<Z<z_{\alpha}\right)=1-\alpha$

The ends of the ranges were determined with the confidence coefficient of $1-\alpha=0.95$.

The next element of the research is determining the confidence intervals for the structure indicators, which allows for the analysis of the share of individual traits in the entire population based on data from the sample $[49,50]$. The confidence interval for the structure index is determined based on a large sample (obtained in a randomized sampling) of a specific variant of the analyzed research feature from the entire statistical population based on the formula: 


$$
P\left(\frac{m}{n}-u_{\alpha} \sqrt{\frac{\frac{m}{n}\left(1-\frac{m}{n}\right)}{n}}<p<\frac{m}{n}+u_{\alpha} \sqrt{\frac{\frac{m}{n}\left(1-\frac{m}{n}\right)}{n}}\right)=1-\alpha
$$

where:

$m$-number of elements highlighted in the sample,

$n$-sample size.

The value of $u_{\alpha}$ statistics from the table of the cumulative distribution function for a standard normal random variable for $1-\frac{\alpha}{2}$.

In the last stage of the study, the confidence interval for the mean was used to assess the qualitative variables. In this case, with a representative sample, the generalization of the research results to the entire population is possible. The confidence interval for the mean is determined according to the formula:

$$
P\left(\bar{x}-\frac{u_{\alpha} S}{\sqrt{n}}<m<\bar{x}+\frac{u_{\alpha} S}{\sqrt{n}}\right)=1-\alpha
$$

where:

$\bar{x}$-arithmetic mean calculated on the n-element sample population,

$s$-sample estimation of standard deviation,

$u_{\alpha}$-the value of a random variable $\mathrm{U}$ with a standardized normal distribution.

All tests and the determination of the confidence intervals were performed with the confidence coefficient of $1-\alpha=0.95$.

The methods described above have been supplemented with cluster analysis-Ward's agglomeration method. Ward's method has been thoroughly described in many publications [51-54].

Ward's method can be presented in a few steps [54]:

1. Normalization, which is normally used due to possible scale differences between questions $(j)$ :

$$
m_{k, j}=\frac{x_{k, j}-x_{m n, j}}{s}
$$

where:

$x_{k j}$-answer value $(x)$ to questions $(j)$ about users $(k)$,

$x_{m j}$ - mean of the answer (mn) to question $(j)$,

$s_{j}$-standard deviation (s) for question $(j)$,

$m_{k j}$-normalized response value $(m)$.

2. Determine the distance $(d)$ between two users or clusters ( $k$ and $l)$-calculated from the square Euclidean distance using normalized values for the total number of questions $(q)$ :

$$
d(k, l)=\sum_{j=1}^{q}\left(m_{k j}-m_{l j}\right)^{2}
$$

3. Users or clusters with minimal distance to each other will be unified into a new cluster $(k+l)$. If the new cluster exists, its distances have to be redefined toward all other users or clusters $(a)$. Different clustering methods use different algorithms for the calculation of new distances. Ward's method calculates the optimal minimum distance taking into account the number of users in the clusters.

$$
d(a, k+l)=\frac{\left(N_{a}+N_{k}\right) * d(a, k)+\left(N_{a}+N_{l}\right) * d(a, l)-N_{a} * d(k, l)}{N_{a}+N_{k}+N_{l}}
$$

where:

$N_{a}$-number of users $(a)$ in the cluster, 
$N_{k}$-number of users $(k)$ in the cluster,

$N_{l}$-number of users $(l)$ in the cluster.

\subsection{Results}

The necessary condition, which had to be met by the companies participating in the study, was a declaration on the availability of R\&D facilities and on the cooperation with users during research and development. The full study covered 137 entities, but only 57 enterprises participated therein. Assuming that the indicated features are present in approximately $80 \%$ of the population (fraction size p), the required number of entities for the study is 56 enterprises. This allows us to conclude that the obtained sample (with the confidence coefficient of $1-\alpha=0.95$ ) is representative, and the obtained results can be generalized to all enterprises in this group.

Before starting the analyses, it is necessary to check whether the studied variables are dependent. As the obtained responses were measured on a nominal scale, the Pearson $\chi^{2}$ test of independence was used to assess their dependence. Seventy-seven variables characterizing the analyzed phenomenon were taken into account. Table 1 shows the values of the statistics $\chi^{2}$ and the values of the probability of rejecting the null hypothesis about the independence of the analyzed variables. Table 1 lists only those variables that meet the assumed conditions, so they can be used for further analysis (along with the probability) between the studied variables.

Table 1. The value of the statistics $\chi^{2}$.

\begin{tabular}{|c|c|c|}
\hline & Pairs of Questions & $\begin{array}{l}\text { Statistic } \chi^{2} \text { and } \\
\text { Probabilities }\end{array}$ \\
\hline \multirow{15}{*}{$\begin{array}{l}\text { a109-crowdsourcing } \\
\text { usage-communicating } \\
\text { with a large number of users } \\
\text { of the company's } \\
\text { product/service in order to } \\
\text { obtain knowledge and } \\
\text { opinions about the } \\
\text { product/service } \\
\text { (user feedback) }\end{array}$} & a10-did the company launch a new/improved product to the market & $13.0288[0.0014]$ \\
\hline & a11-the number of product innovations introduced & $113.1426[0.0000]$ \\
\hline & $\begin{array}{c}\text { a17-did the company introduce a new or significantly improved } \\
\text { technological process to the market }\end{array}$ & $13.0288[0.0014]$ \\
\hline & a34-the number of people employed in the area of $R \& D$ & $17.5919[0.0245]$ \\
\hline & a35-the number of employees with a doctoral degree & $28.9250[0.0074]$ \\
\hline & a36- the number of employees with the habilitated doctor degree & $15.9026[0.0102]$ \\
\hline & $\begin{array}{l}\text { a38-the purpose of research and development is to shorten the response } \\
\text { time to customer needs }\end{array}$ & $14.7227[0.0094]$ \\
\hline & $\begin{array}{l}\text { a50-the purpose of research and development is to meet the regulations } \\
\text { and standards }\end{array}$ & $13.0734[0.0215]$ \\
\hline & a55-the percentage of revenues allocated to $R \& D$ in the last three years & $16.8948[0.0312]$ \\
\hline & a57-R\&D support tools used: tax credits & $13.3853[0.0018]$ \\
\hline & a58-R\&D support tools used: grants & $12.8851[0.0236]$ \\
\hline & $\begin{array}{l}\text { a69-more effective management of intellectual property rights as a } \\
\text { result of R\&D }\end{array}$ & $12.5792[0.0027]$ \\
\hline & $\begin{array}{l}\text { a73-the possibility of joint implementation of R\&D projects with larger } \\
\text { companies }\end{array}$ & $9.2037[0.0100]$ \\
\hline & a77—the number of completed R\&D projects & $31.0985[0.0000]$ \\
\hline & a87-cooperation with units of the Polish Academy of Sciences & $6.5156[0.0384]$ \\
\hline
\end{tabular}

Source: own elaboration.

The study's subject is to determine the level of dependence between crowdsourcing in the surveyed companies and the elements characterizing the innovation and R\&D activities. For the purposes of the analysis, the Kendall tau and V-Cramer correlation coefficients were determined. Only those that are statistically significant were selected for further research. The calculation results are shown in Table 2. 
Table 2. The value of the Kendall and V-Cramer tau correlation coefficients.

\begin{tabular}{|c|c|c|c|}
\hline & Pairs of Questions & tau Kendalla $\left(\tau_{b}\right)$ & V-Cramera $(V)$ \\
\hline \multirow{15}{*}{$\begin{array}{l}\text { a109_crowdsourcing } \\
\text { usage-communicating } \\
\text { with a large number of } \\
\text { users of the company's } \\
\text { product/service in order } \\
\text { to obtain knowledge and } \\
\text { opinions about the } \\
\text { product/service } \\
\text { (user feedback) }\end{array}$} & $\begin{array}{l}\text { a10-did the company launch a new/improved product } \\
\text { to the market }\end{array}$ & -0.4347 & 0.4781 \\
\hline & a11-the number of product innovations introduced & 0.8858 & 0.8164 \\
\hline & $\begin{array}{l}\text { a17-did the company introduce a new or significantly } \\
\text { improved technological process to the market }\end{array}$ & 0.4347 & 0.4781 \\
\hline & a34-the number of people employed in the area of R\&D & 0.3241 & 0.3928 \\
\hline & a35-the number of employees with a doctoral degree & 0.2747 & 0.2551 \\
\hline & $\begin{array}{c}\text { a36-the number of employees with the habilitated doctor } \\
\text { degree }\end{array}$ & 0.2173 & 0.2735 \\
\hline & $\begin{array}{l}\text { a38-the purpose of research and development is to } \\
\text { shorten the response time to customer needs }\end{array}$ & -0.2489 & 0.2878 \\
\hline & $\begin{array}{c}\text { a50-the purpose of research and development is to meet } \\
\text { the regulations and standards }\end{array}$ & -0.2198 & 0.2322 \\
\hline & $\begin{array}{c}\text { a55-the percentage of revenues allocated to R\&D in the } \\
\text { last three years }\end{array}$ & -0.2705 & 0.3849 \\
\hline & a57-R\&D support tools used: tax credits & 0.2357 & 0.2437 \\
\hline & a58-R\&D support tools used: grants & -0.2174 & 0.2249 \\
\hline & $\begin{array}{l}\text { a69-more effective management of intellectual property } \\
\text { rights as a result of } R \& D\end{array}$ & 0.2051 & 0.2127 \\
\hline & $\begin{array}{l}\text { a73-the possibility of joint implementation of } R \& D \\
\text { projects with larger companies }\end{array}$ & 0.1877 & 0.2018 \\
\hline & a77-the number of completed R\&D projects & 0.5598 & 0.5222 \\
\hline & $\begin{array}{c}\text { a87-cooperation with units of the Polish Academy } \\
\text { of Sciences }\end{array}$ & 0.2791 & 0.3381 \\
\hline
\end{tabular}

Source: own elaboration.

As can be seen in Table 2, the values of the Kendall and V-Cramer tau correlation coefficients are similar. As previously mentioned, the Cramer V-coefficient ranges from 0 to 1 , so one can only analyze the strength of the relationship, not its direction. As written by Kearney, "Cramer's statistic ( . . ) facilitates the interpretation of nominal-variable association estimates, given this index ranges from 0 to +1 . A higher $\mathrm{VC}$ indicates a stronger association" [55].

The analysis of the obtained correlation coefficients shows that a very high correlation occurs only in the case of the number of product innovations introduced by the enterprise $\left(\tau_{b}=0.8858 / V C=0.8164\right)$, and a high one only in the case of the number of completed $R \& D$ projects $\left(\tau_{b}=0.5598 / V C=0.5222\right)$. Average dependencies were recorded when entities introduce a new or improved product or service to the market $\left(\tau_{b}=-0.4347 / V C=0.4781\right)$ and when they introduce a new or significantly improved technological process to the market $\left(\tau_{b}=0.4347 / V C=0.4781\right)$. An average correlation was also recorded for the number of people employed in the $R \& D$ area $\left(\tau_{b}=0.3241 / 0.3928\right)$. The remaining analyzed variables showed a weak correlation with crowdsourcing activities.

Since the analyzed sample is representative, the obtained correlation coefficients can be generalized to the entire population, using the confidence interval for the correlation coefficient (Table 3). That will allow determining the range within which the analyzed relationships are shaped in the entire population.

Clearly, the smaller the relationship between the variables, the greater the span of the correlation coefficient for the population. Therefore, the analysis of the degree of dependence for all enterprises is challenging. Only in the case of variable a11 can the obtained interval be treated as reliable. 
Table 3. Confidence intervals for the correlation coefficient.

\begin{tabular}{|c|c|c|}
\hline Variable & $\begin{array}{l}\text { Confidence Interval } \\
\text { (tau Kendall) }\end{array}$ & $\begin{array}{l}\text { Confidence Interval } \\
\text { (V-Cramer) }\end{array}$ \\
\hline launching a new/improved product/service on the market & $-0.5624<\rho<-0.2868$ & $0.3363<\rho<0.5987$ \\
\hline the number of product innovations introduced & $0.8430<\rho<0.9175$ & $0.7510<\rho<0.8659$ \\
\hline $\begin{array}{l}\text { introduction to the market of a new or significantly improved } \\
\text { technological process }\end{array}$ & $0.2868<\rho<0.5624$ & $0.3363<\rho<0.5987$ \\
\hline the number of people employed in the area of $R \& D$ & $0.1641<\rho<0.4675$ & $0.2398<\rho<0.5268$ \\
\hline the number of employees with a doctoral degree & $0.1109<\rho<0.4240$ & $0.0900<\rho<0.4065$ \\
\hline the number of employees with the habilitated doctor degree & $0.0502<\rho<0.3726$ & $0.1096<\rho<0.4229$ \\
\hline $\begin{array}{l}\text { the purpose of research and development is to shorten the response time to } \\
\text { customer needs }\end{array}$ & $-0.4010<\rho<-0.0834$ & $0.1249<\rho<0.4356$ \\
\hline $\begin{array}{l}\text { the purpose of research and development is to meet the regulations } \\
\text { and standards }\end{array}$ & $-0.3748<\rho<-0.0528$ & $0.0658<\rho<0.3860$ \\
\hline the percentage of revenues allocated to $R \& D$ in the last three years & $-0.4203<\rho<-0.1064$ & $0.2310<\rho<0.5200$ \\
\hline R\&D support tools used: tax credits & $0.0695<\rho<0.3892$ & $0.0779<\rho<0.3963$ \\
\hline R\&D support tools used: grants & $-0.3727<\rho<-0.0503$ & $0.0581<\rho<0.3794$ \\
\hline more effective management of intellectual property rights as a result of $R \& D$ & $0.0374<\rho<0.3615$ & $0.0454<\rho<0.3684$ \\
\hline $\begin{array}{l}\text { the possibility of joint implementation of R\&D projects with } \\
\text { larger companies }\end{array}$ & $0.0194<\rho<0.3457$ & $0.0340<\rho<0.3585$ \\
\hline the number of completed R\&D projects & $0.4317<\rho<0.6658$ & $0.3874<\rho<0.6351$ \\
\hline cooperation with units of the Polish Academy of Sciences & $0.1156<\rho<0.4279$ & $0.1794<\rho<0.4797$ \\
\hline
\end{tabular}

Source: own elaboration.

Some interesting information can also be provided by the variables' structure analysis, that has the most significant impact on the phenomenon of crowdsourcing-both in the sample and in the general population. Additionally, it gives a broader picture of the studied group of enterprises and the entire population. In the surveyed entities, $57.89 \%$ of enterprises introduced a new or improved product or service (a10) to the market in the analyzed period. The number of innovations introduced varied (a11). As much as $35.09 \%$ of the respondents introduced 1 to 4 product innovations, $33.33 \% 5$ to 9 , and $22.81 \% 10$ to 19 , while the rest introduced more than 20 . In the case of a new or significantly improved technological process (a17), the opposite is true. Only $42.11 \%$ of the surveyed entities performed such activity. The purpose of activity for $45.61 \%$ of the entities is to shorten the response time to customer needs (a38), and $7.02 \%$ of enterprises identify the compliance with regulations and standards as the purpose. These elements have little relation to the idea of crowdsourcing, which was additionally confirmed by the earlier analysis of correlation coefficients. All entities allocate part of their revenues to R\&D activities (a55). In the analyzed period, the largest part of the respondents-29.82\%—allocated from $5 \%$ to $10 \%$ of income for this purpose, $21.05 \%$ from $3 \%$ to $5 \%, 17.54 \%$ from $1 \%$ to $2 \%$, and $15.80 \%$ above $10 \%$ of income, while $15.79 \%$ of respondents less than $1 \%$. The increase in expenditure on research and development activities in $43.86 \%$ of entities is influenced by the possibility of a more effective management of intellectual property rights as a result of R\&D activities (a69) and the possibility of a joint implementation of research and development projects with larger enterprises (a73) in 7.02\% of the respondents. Respondents can use various tools to support research and development activities. As much as $85.96 \%$ benefit from tax reliefs (a57) and 61.40\% from grants (a58). All enterprises carried out research and development projects during the analyzed period (a77), although their number varied. As much as $29.83 \%$ of entities implemented over $20,29.82 \%$ from 11 to $15,22.81 \%$ from 6 to 10 , and the rest between 16 and 20 . In the case of $33.33 \%$ of enterprises, these projects were implemented in cooperation with the units of the Polish Academy of Sciences (a87). The 
above analysis was extended to examine the confidence intervals for the structure index (Table 4).

Table 4. Confidence intervals for the structure index.

\begin{tabular}{|c|c|c|}
\hline \multicolumn{2}{|l|}{ Variable } & \multirow{3}{*}{$\begin{array}{l}\text { Confidence Interval } \\
29.29 \%<p<54.92 \% \\
45.08 \%<p<70.71 \%\end{array}$} \\
\hline launching a new/improved product/service on & no & \\
\hline the market & yes & \\
\hline \multirow{4}{*}{ the number of product innovations introduced } & $1-4$ & $22.70 \%<p<47.48 \%$ \\
\hline & $5-9$ & $21.10 \%<p<45.57 \%$ \\
\hline & 10-19 & $11.91 \%<p<33.70 \%$ \\
\hline & $20-29$ & $1.43 \%<p<16.12 \%$ \\
\hline \multirow{2}{*}{$\begin{array}{l}\text { introduction to the market of a new or } \\
\text { significantly improved technological process }\end{array}$} & no & $45.08 \%<p<70.71 \%$ \\
\hline & yes & $29.29 \%<p<54.92 \%$ \\
\hline \multirow{2}{*}{$\begin{array}{l}\text { the number of people employed in the area of } \\
\qquad R \& D\end{array}$} & no & $41.46 \%<p<67.32 \%$ \\
\hline & yes & $32.68 \%<p<58.54 \%$ \\
\hline \multirow{2}{*}{ the number of employees with a doctoral degree } & no & $86.35 \%<p<99.61 \%$ \\
\hline & yes & $0.39 \%<p<13.65 \%$ \\
\hline \multirow{5}{*}{$\begin{array}{c}\text { the number of employees with a habilitated } \\
\text { doctor degree }\end{array}$} & less than $1 \%$ of the & $6.32 \%<p<25.26 \%$ \\
\hline & $1-2 \%$ & $7.67 \%<p<27.42 \%$ \\
\hline & $3-5 \%$ & $10.47 \%<p<31.64 \%$ \\
\hline & $5-10 \%$ & $17.95 \%<p<41.70 \%$ \\
\hline & More than $10 \%$ & $6.32 \%<p<25.26 \%$ \\
\hline \multirow{2}{*}{$\begin{array}{l}\text { the purpose of research and development is to } \\
\text { shorten the response time to customer needs }\end{array}$} & no & $5.02 \%<p<23.05 \%$ \\
\hline & yes & $76.95 \%<p<94.98 \%$ \\
\hline \multirow{2}{*}{$\begin{array}{l}\text { the purpose of research and development is to } \\
\text { meet the regulations and standards }\end{array}$} & no & $25.96 \%<p<51.23 \%$ \\
\hline & yes & $48.77 \%<p<74.04 \%$ \\
\hline \multirow{2}{*}{$\begin{array}{c}\text { the percentage of revenues allocated to R\&D in } \\
\text { the last three years }\end{array}$} & no & $43.26 \%<p<69.02 \%$ \\
\hline & yes & $30.98 \%<p<56.74 \%$ \\
\hline \multirow{2}{*}{ R\&D support tools used: tax credits } & no & $86.35 \%<p<99.61 \%$ \\
\hline & yes & $0.39 \%<p<13.65 \%$ \\
\hline \multirow{4}{*}{ R\&D support tools used: grants } & $6-10$ & $11.91 \%<p<33.70 \%$ \\
\hline & $11-15$ & $17.95 \%<p<41.70 \%$ \\
\hline & $16-20$ & $7.67 \%<p<27.42 \%$ \\
\hline & 21 and more & $17.95 \%<p<41.70 \%$ \\
\hline \multirow{2}{*}{$\begin{array}{l}\text { more effective management of intellectual } \\
\text { property rights as a result of R\&D }\end{array}$} & no & $54.43 \%<p<78.90 \%$ \\
\hline & yes & $21.10 \%<p<45.57 \%$ \\
\hline
\end{tabular}

Source: own elaboration.

As some of the variables could not be presented in the form of intervals, their short description using basic statistical measures is presented below (Table 5).

In summarizing Table 3, it can be noted that the surveyed enterprises employ an average of four people in the $R \& D$ area (in the population, $3.47<\mathrm{m}<4.11$ ). On average, eight people work in the surveyed entities with a doctoral degree (in the population, $6.22<$ $\mathrm{m}<9.36$ ) and two people with the academic degree of habilitated doctor (in the population, $1.28<\mathrm{m}<2.09$ ). However, it should be noted that these groups are characterized by substantial deviations from the mean (Vs).

Figure 1 supplements the above studies, presenting the results of calculations using one of the cluster analysis methods, i.e., the Ward agglomeration method. 
Table 5. The basic characteristics of quantitative variables.

\begin{tabular}{ccccccc}
\hline Variable & Min & Max & $\bar{x}$ & M & D & Vs \\
\hline the number of people employed in the area of R\&D & 1 & 5 & 3.7895 & 4 & 5 & $32.98 \%$ \\
the number of employees with a doctoral degree & 0 & 25 & 7.7895 & 7 & multiple & $77.47 \%$ \\
the number of employees with the habilitated doctor degree & 0 & 5 & 1.6842 & 2 & 0 & $91.95 \%$ \\
\hline
\end{tabular}

min—lowest value in the sample; min—lowest value in the sample; $\bar{x}$ —arithmetic mean; M-median; D—dominant; vs.—the coefficient of variation. Source: own elaboration.

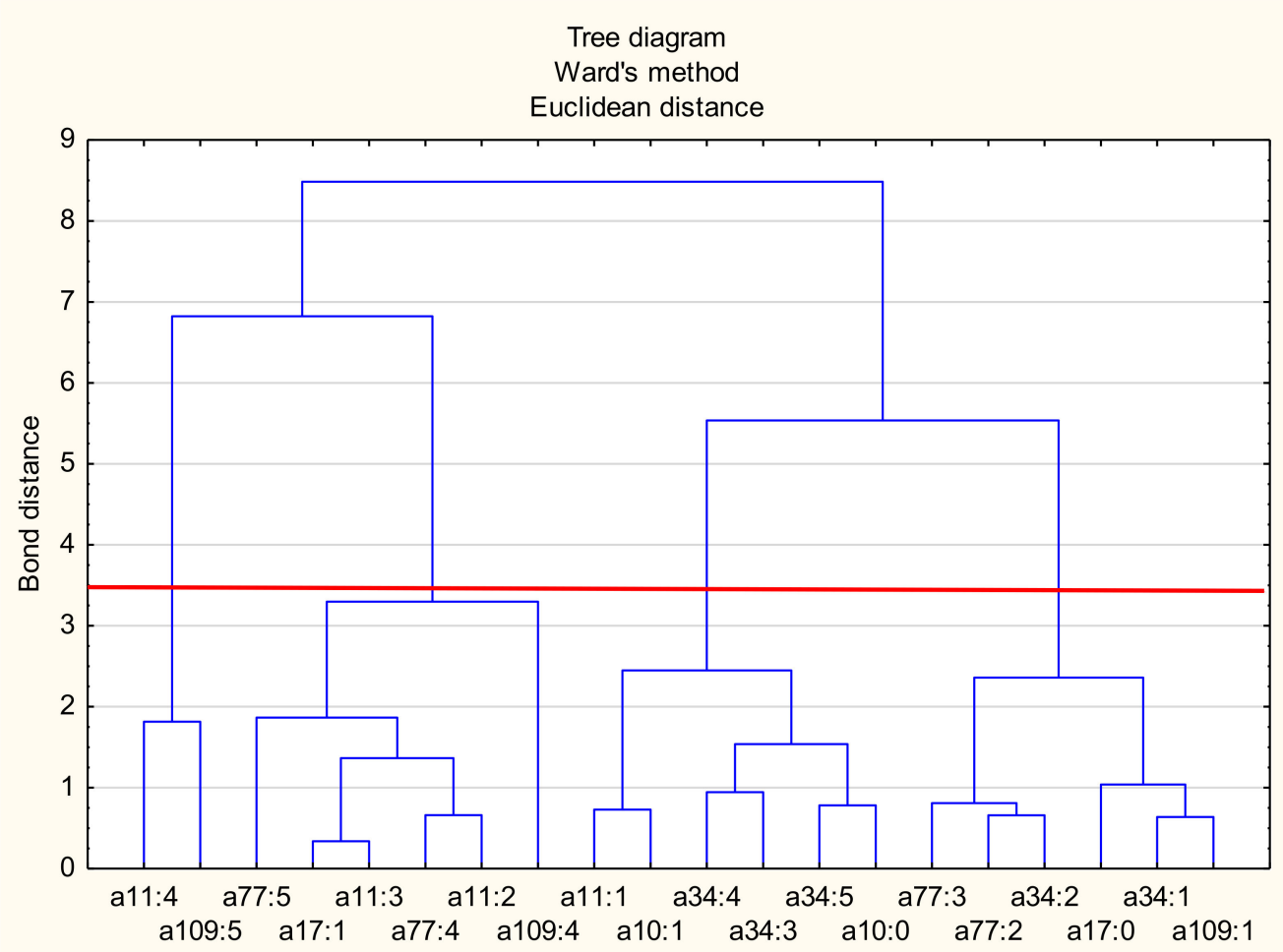

Figure 1. Diagram of hierarchical classification of variable categories-Ward's method. Source: own elaboration.

The method used allows for the observation of clear relationships between the individual categories of variables, and this confirms the research results obtained earlier. On Figure 1, three groups of enterprises are clearly distinguished:

1. Enterprises that very often communicate with a large number of users of a product/service in order to obtain feedback from users (a109: 5) introduced from 20 to 29 product innovations (a11: 4).

2. Enterprises frequently asking users for feedback on products or services (a109: 4) are entities that introduced 5 to 9 (a11: 2) and 10 to 19 (a11: 3) product innovations in the analyzed period. These enterprises introduced a new or significantly improved technological process to the market (a17: 1). In the analyzed period, entities frequently using user opinions implemented from 16 to 20 (a77: 4) and 21 and more (a77: 5) research and development projects.

3. Enterprises that occasionally used communication with users (a109: 1) in the analyzed period did not introduce a new or significantly improved technological process (a17: 0). These enterprises also did not introduce new or improved products and services to the market (a10: 0). Firms that used feedback from consumers sporadically implemented 6 to 10 (a77: 2) or 11 to 15 (a77: 3) R\&D projects. It should be noted here that this group of entities employs from 1 to 5 (a31: 1) or from 6 to 10 (a34: 2) people in the research and development area. 


\section{Discussion}

The aim of the research was to determine the impact of crowdsourcing on various attributes of innovation activity in the R\&D departments of enterprises in terms of userdriven innovation. When starting the research, we assumed that there was a relationship between crowdsourcing and the results achieved in the innovation activity of the studied enterprises. Our research led, in general, to a positive verification of this hypothesis. However, analyzing the results of the research in detail, we concluded that although there is a obvious correlation between crowdsourcing and some elements of innovation activity, not all of them correlate. The implementation of crowdsourcing affects mostly the number of product innovations introduced by the company and the number of completed R\&D works. This conclusion is not surprising, as it confirms even more the belief that crowdsourcing increases the efficiency and effectiveness of innovation processes.

The definition of crowdsourcing is not unequivocal. Some researchers use different definitions of crowdsourcing [56,57]. An analysis of crowdsourcing definitions that was very helpful for this article was proposed by Estelle's-Arolas and Gonzalez-Ladron-deGuevara [10]. The authors notice that the term "crowdsourcing" is a term in its infancy and will change over the years. Crowdsourcing can be used in connection with financing, voting, knowledge, and innovation. Some authors identify crowdsourcing with the issue of open innovation, but other researchers hold a completely different view.

In this regard, the crowdsourcing and innovation identified and investigated in our article are in line with the literature review elaborated by Chanal and Caron-Fasal in 2008 [58]. On the opposite side of the scientific argument is the definition proposed by Schenk and Guittard [59].

Our research on the role of crowdsourcing in terms of innovation is in line with the existing literature on the subject, where the concept of user-driven innovation is often used as the innovation model for understanding innovation systems [4,5].

The role of virtual communities in the transfer of knowledge is also often underlined [7]. Researchers also indicate (which is in line with our research) the role of crowdsourcing in creating innovation, thanks to the involvement of users in this process. Based on the analysis of the available literature sources, it can be seen that crowdsourcing is most often used in the case of new innovative products [8]. This is in line with the results of our research, where over $55 \%$ of enterprises introduced a new or improved product in the analyzed period.

Advances in information and communication technology development allow access to an unlimited and direct source of information, that magnifies the impact of any activity by simply disseminating it through appropriate forums, social networks, or specific platforms. Aldino Fernandez Blanco et al. conducted a retrospective or AAR (After Action Review) analysis to identify both successful and unsuccessful projects [60]. The authors pointed out how important it is to know about the decisions that were made in the project while trying to identify actions that would ensure success or protect against the failure of the crowdfunding project. Crowdfunding is a narrower concept than crowdsourcing because it concerns only one area of community use-funding. However, the conclusions of the authors in their article may also be applied to research related to the use of crowdsourcing in innovative activities.

A valuable solution used by other researchers, which is worth considering in the next stages of research on the links between crowdsourcing and enterprise innovation, is to identify and include various clusters in the research. The importance of identifying clusters and their attributes allows project managers to use a tool that helps to estimate the economic and financial viability of crowdfunding an ongoing project. In this way, resources and efforts can be devoted to improving the quality and benefit ratios of the project.

Walter and Back [61] noted that due care must be taken when using crowdsourcing to stimulate innovation in the enterprise. However, we are convinced of its significant value when understanding the market conditions and recognizing the potential external effects that may occur after the implementation of a specific strategy. The authors indicated that 
the rewards offered, market maturity, duration, and brand strength all influence the number of innovative ideas emerging. The results of their research can be indirectly compared with the results of our analysis on the relationship between crowdsourcing and innovative activity. It is worth noting that the issues related to crowdsourcing and the use of UDI are just developing and all conclusions are made on the basis of partial research.

Furthermore, the integration of the customer and employee wisdom into decisionmaking processes in $\mathrm{R} \& \mathrm{D}$ departments is also very important. Callaghan [62] pointed out that some scientists are concerned about the declining returns on investment in research and development (R\&D), as well as the lack of increase in the number of patents, which is even referred to as the "death of innovation". Callaghan also pointed out that economies of scale are possible in $R \& D$ and states that crowdsourcing can be the key to achieving them in R\&D. This approach is consistent with the one presented in our article. In our research, we have identified factors that are important in determining the relationship between the use of crowdsourcing and elements of innovative activity and R\&D (such as: launching a new or improved product on the market; the number of product innovations introduced; the number of people employed in the area of R\&D; the purpose of research and development is to shorten the response time to customer needs; R\&D support tools used: tax credits and grants; cooperation with research units etc.).

From an economic perspective, crowdsourcing provides greater knowledge, understanding, and awareness of industrial processes that improve decision-making in terms of timeliness and efficiency [34,63].

The tools we have examined and identified to support research and development activities—-such as, i.e., tax breaks and subsidies—are also listed in the literature on the subject, which may be illustrated by the OECD report in this area [64]. Other researchers, however, point out that in the development of new products (NPD—new product development), apart from tax and financial incentives [65], the management of information obtained from clients [66], the specification of the project design [67], and the characteristics of the crowd involved in innovative projects play a key role.

Knowledge, skills, and the individual characteristics of crowd members involved in the development of a product or service have a significant impact on the product design quality created in the crowdsourcing formula. The views presented by Poetz and Schreier [39] are also confirmed by our research. It is a chance to develop innovation in small and dynamic enterprises located in developing EU regions, which do not have sufficiently developed R\&D departments. Therefore, crowdsourcing platforms in the near future will be an important factor stimulating innovation processes in companies.

Our research highlights the importance of digital technologies in collecting, developing, monitoring, and analyzing the economic links between crowdsourcing and innovation in companies. According to the literature on the development of enterprises, digital technologies enable a large contribution of customers to the improvement of products and services through a developed network where feedback on the purchases made can be obtained [68]. Therefore, we argue that planning, developing, and implementing new ideas and inventions can be realized by systematically taking into account the opinions of customers and their knowledge regarding the development of the usability of products and services. This will bring tangible benefits to all parties involved in the process. This participatory and inclusive approach is supported by theoretical literature and our research. The proposed framework emphasizes, in particular, the importance of a multidimensional approach, and the successes of the surveyed enterprises using crowdsourcing confirm the correctness of the presented hypothesis.

Therefore, we do not claim that these critical issues have not been previously highlighted and discussed in the literature, but that our result shows, in an integrated framework, existing factors, domains, and goals, and therefore makes a useful contribution to improving the understanding and awareness of the relationship between crowdsourcing and innovation management in companies. 


\section{Conclusions}

Customers and their voice play a decisive role here. Listening to the voice of customers reduces the costs of the innovation process. It is also the shortest and simplest path to product innovation. Moreover, it can be further argued that there is a key premise for enterprises to opt for crowdsourcing.

Our research, conducted in Polish enterprises, has shown that crowdsourcing is mostly used when looking for ideas for a new product or innovation process or when looking for ideas for changes in an existing product or process. This proves that entrepreneurs understand that it is the simplest and a relatively cheap way to match products changing at an ever-faster pace and in an increasingly unpredictable way to the needs and preferences of customers, on the basis of "why open the door with the key when it is open ?". As already stated, guessing what the client wants today-in times of fierce competition-is timeconsuming and expensive. It should also be remembered that the life cycles of products are getting shorter, despite the application of the principles of sustainable development.

There is one more issue that needs to be considered-entrepreneurs are becoming more and more convinced that coming up with innovative ideas is no longer the exclusive domain of experts. The community is taking over that responsibility. Research proves the theory of the crowd. Crowdsourcing fits perfectly with contemporary conditions that require companies to go outside, build active, "living" relationships with the environment, and establish an authentic, i.e., two-way communication. One might think that the shortage of employees forces companies to use crowdsourcing. Research has shown that the use of crowdsourcing does not depend on the number of people employed in the R\&D area.

Therefore, it is not some (crisis) situation that forces the company to use crowdsourcing. Rather, this method is already considered as a basic tool of company management, and customers are perceived as "external members" of the company. Moreover, the competences of employees, and more specifically their academic degrees, do not influence the decision to use crowdsourcing. It also does not matter what part of the revenue is allocated to $R \& D$ in the enterprise, and whether any $R \& D$ support tools are used. These are very interesting conclusions, important both from a theoretical and a practical perspective. This means that company managers do not necessarily need to use the knowledge of employees with a scientific background. Neither do they have to look for supporting tolls such as grants, tax exemptions, or external financing to be innovative. This is a very important result, taking into account the fact that innovation activity is often described as one that cannot take place without external support due to its high costs. The most important result and conclusion is therefore that companies can be innovative when they use crowdsourcing as a main source of innovation.

The above research results show a cooperation with consumer results in the development of innovative activities in enterprises. Using feedback from users of products and services (crowdsourcing) results in the introduction of more product innovations, the introduction of new or significantly improved technological processes, as well as the implementation of a greater number of research and development projects. Thus, the main hypothesis was confirmed, and the aim of the article was achieved.

The innovative nature of the research and analyses carried out implies certain limitations. Due to the threat posed by competition, enterprises are reluctant to participate in research, especially if they concern their innovative activities, which are highly risky and show a competitive advantage (hence, they are subject to the rigor of trade secrets). Consequently, there is a certain mental block on the part of companies. Furthermore, the study that was conducted in the article concerned 57 enterprises operating in Poland. The authors realize that the sample may not be representative of the entire population of enterprises in Poland, but it was selected very carefully and systematically. The rankings of the most innovative companies that have $R \& D$ departments at the same time were used. The list of respondents was selected, among others, on the basis of indications of a recognized consulting company such as Deloitte, as well as a nationwide unit- the Institute of Economic Sciences of the Polish Academy of Sciences. 
Being aware of the limitations of this pioneering study and the lack of the possibility of broader generalizations (that will be explained in the conclusions), it seems justified to believe that the study can be used to draw conclusions about the future of crowdsourcing development in connection with innovation and the R\&D sector. As indicated earlier, in many countries there is a (scientific and practical) discussion about the importance of innovation and crowdsourcing. Our research gives a new contribution to the ongoing global discussion around the discussed research topic. It also allows one to draw conclusions that can be used as a guide for other companies in Poland and other countries. The article has implications for the use of crowdsourcing in R\&D activities.

It is undisputed that crowdsourcing requires further research, both from a theoretical and a practical perspective. The desired research directions in this area include, first and foremost, all aspects of the effectiveness and efficiency of crowdsourcing as stimulants of innovative processes, the diversification of the premises for the use of crowdsourcing in various fields of economic and non-economic activity, the motives of the "crowd", and behavioral determinants of the relations between animators and crowdsourcing participants. The observed enthusiasm for crowdsourcing should not focus only on its advantages, but also raise questions about its disadvantages and limitations. Current problems, such as Covid-19, also provide inspiration for research. It is worth answering the question of whether the pandemic influenced crowdsourcing and how.

The conclusions from our research cannot be applied to all companies, but we strongly believe that they can be helpful in the R\&D departments of those companies that also undertake crowdsourcing cooperation. The results of our research may be the beginning of a valuable scientific discussion on the possibility of a wider use of crowdsourcing in innovative activities of companies.

Author Contributions: Conceptualization, K.S.-D.; methodology, K.S.-D and A.B.; software, A.B.; validation, K.S.-D., I.D., A.B., A.K.-S., K.S., and G.I.; formal analysis, K.S.-D., I.D., A.B., A.K.-S., K.S., R.D. and G.I; investigation, K.S.-D., I.D., A.B., A.K.-S., K.S., R.D. and G.I.; writing-original draft preparation, K.S.-D., I.D., A.B., A.K.-S., K.S., and G.I.; writing-review and editing, K.S.-D., I.D., A.B., A.K.-S., K.S., R.D. and G.I.; visualization, K.S.-D., I.D. and R.D.; supervision, K.S.-D.; project administration. K.S.-D.; funding acquisition, K.S.-D. All authors have read and agreed to the published version of the manuscript.

Funding: The project is financed within the framework of the program of the Ministry of Science and Higher Education, under the name "Regional Excellence Initiative", in the years 2019-2022. (project number: 001/RID/2018/19; amount of financing: PLN 10,684,000.00), and the statutory funds of the Institute of Management, University of Szczecin.

Institutional Review Board Statement: Not applicable.

Informed Consent Statement: Not applicable.

Data Availability Statement: Not applicable.

Conflicts of Interest: The authors declare no conflict of interest.

\section{References}

1. Howe, J. The rise of crowdsourcing. Wired Mag. 2006, 14,1-5. Available online: http://www.wired.com/2006/06/crowds/ (accessed on 24 May 2021).

2. Wise, E.; Hoegenhaven, C.; Nordic Innovation Centre. User-Driven Innovation-Context and Cases in the Nordic Region; Lund University: Lund, Sweden, 2008.

3. Trott, P.; Van Der Duin, P.; Hartmann, D. Users as innovators? Exploring the limitations of user-driven innovation. Prometh. Crit. Stud. Innov. 2013, 31, 125-138. [CrossRef]

4. Bogers, M.; Afuah, A.; Bastian, B. Users as innovators: A review, critique, and future research directions. J. Manag. 2010, 36, 857-875. [CrossRef]

5. Baldwin, C.; Hienerth, C.; von Hippel, E. How user innovations become commercial products: A theoretical investigation and case study. Res. Policy 2006, 35, 1291-1313. [CrossRef]

6. Jelonek, D. The role of the Internet in open innovations model's development. Bus. Inform. 2012, 1, 38-47.

7. Rheingold, H. The Virtual Community: Homesteading on the Electronic Frontier; MIT Press: London, UK, 2000. 
8. Howe, J. Crowdsourcing: Why the Power of the Crowd Is Driving the Future of Business; Crown Business: London, UK, 2008.

9. Sprinet.pl to Platforma Działajaca w Oparciu o Zasady Crowdsourcingu. Available online: http://www.pi.gov.pl/PARP/ chapter_86197.asp?soid=A26FF3370CE4489D8D5818356BC76625 (accessed on 30 June 2021).

10. Estellés-Arolas, E.; González-Ladrón-de-Guevara, F. Towards an integrated crowdsourcing definition. J. Inf. Sci. 2012, 38, 189-200. [CrossRef]

11. Ling, P. An Empirical Study of Social Capital in Participation in Online crowdsourcing. Computer 2010, 7, 1-4.

12. Sloane, P. The brave new world of open innovation. Strateg. Dir. 2011, 27, 3-4. [CrossRef]

13. Boudreau, K.J.; Lakhani, K.R. Using the Crowd as an Innovation Partner. Harv. Bus. Rev. 2013, 91, 60-69.

14. Brabham, D.C. Crowdsourcing. The MIT Press Essential Knowledge Series. 2013. Available online: https://wtf.tw/ref/brabham. pdf (accessed on 12 February 2021).

15. Kaewchur, O.; Anussornnitisarn, P.; Pastuszak, Z. The Mediating Role of Knowledge Sharing on Information Technology and Innovation. Int. J. Manag. Knowl. Learn. 2013, 2, 227-242.

16. Johannssen, J.-A.; Olsen, B. The future of value creation and innovations: Aspects of a theory of value creation and innovation in a global knowledge economy. Int. J. Inf. Manag. 2010, 30, 502-511. [CrossRef]

17. Szopik-Depczynska, K.; Barczak, A.; Dembińska, I.; Wisniewska, J. The Impact of the Internet on User-Driven Innovation Usage in R\&D Departments: A Case Study of Poland. Eur. Res. Stud. J. 2020, XXIII, 247-263. [CrossRef]

18. Khan, V.J.; Papangelis, K.; Markopoulos, P.; Lykourentzou, I. Marco-Task Crowdsourcing: Engaging the Crowds to Address Complex Problems; Springer: Berlin/Heidelberg, Germany, 2019.

19. Beretta, M.; Søndergaard, H.A. Employee behaviours beyond innovators in internal crowdsourcing: What do employees do in internal crowdsourcing, if not innovating, and why? Creat. Innov. Manag. 2021, 30, 542-562. [CrossRef]

20. Mangiaracina, R.; Perego, A.; Seghezzi, A.; Tumino, A. Innovative solutions to increase last-mile delivery efficiency in B2C e-commerce: A literature review. Int. J. Phys. Distrib. Logist. Manag. 2019, 49, 901-920. [CrossRef]

21. Alhalabi, W.; Lytras, M.; Aljohani, N. Crowdsourcing Research for Social Insights into Smart Cities Applications and Services. Sustainability 2021, 13, 7531. [CrossRef]

22. Schall, D. Service-Oriented Crowdsourcing: Architecture, Protocols and Algorithms; Springer: Berlin/Heidelberg, Germany, 2012.

23. Egger, R.; Gula, I.; Walcher, D. Open Toursim: Open Innovation, Crowdsourcing and Co-Creation Challenging the Tourism Industry; Springer: Berlin/Heidelberg, Germany, 2016.

24. Michail, A.-M.; Gavalas, D. A Crowdsourcing Platform for Promoting Gastronomic Tourism. In Proceedings of the 2019 IEEE International Conference on Pervasive Computing and Communications Workshops (PerCom Workshops), Kyoto, Japan, 11-15 March 2019. [CrossRef]

25. Zhu, Y.; Zhang, S.; Li, Y.; Lu, H.; Shi, K.; Niu, Z. Social weather: A review of croudsourcing-assisted meteorological knowledge services through social cyberspace. Geosci. Data J. 2019, 7, 61-79. [CrossRef]

26. Mariani, A.; Annunziata, A.; Nacchia, F.; Vastola, A. Crowdsourcing in Wine Business: Co-Creation and Fundraising Experiences. In Successful Social Media and Ecommerce Strategies in The Wine Industry; Szolnoki, G., Thach, L., Kolb, D., Eds.; Book Series: Palgrave Pivot; Springer Nature: Basingstoke, UK, 2016. [CrossRef]

27. Thompson, D.C.; Bentzien, J. Crowdsourcing and open innovation in the drug discovery: Recent contributions and future directions. Drug Discov. Today 2020, 25, 2284-2293. [CrossRef]

28. De Mattos, C.A.; Kissimoto, K.O.; Laurindo, F.J.B. The role of information technology for building virtual environments to integrate crowdsourcing mechanisms into the open innovation process. Technol. Forecast. Soc. Chang. 2018, 129, 143-153. [CrossRef]

29. Barczak, A.; Dembińska, I.; Marzantowicz, Ł. Analysis of the Risk Impact of Implementing Digital Innovations for Logistics Management. Processes 2019, 7, 815. [CrossRef]

30. Kohler, T. Crowdsourcing-Based Business Models: How to Create and Capture Value. Calif. Manag. Rev. 2015, 57, 63-84. [CrossRef]

31. Stieger, D.; Matzler, K.; Chatterjee, S.; Ladstaetter-Fussnegger, F. Democratizing strategy. Calif. Manag. Rev. 2012, 54, 44-68. [CrossRef]

32. Palacios-Marqués, D.; Gallego-Nicholls, J.F.; Guijarro-García, M. A recipe for success: Crowdsourcing, online social networks, and their impact on organizational performance. Technol. Forecast. Soc. Chang. 2021, 165. [CrossRef]

33. Dellermann, D.; Lipusch, N.; Ebel, P.; Leimeister, J.M. The potential of collective intelligence and crowdsourcing creation. Int. J. Entrep. Ventur. 2020, 12, 183-207. [CrossRef]

34. Ghezzi, A.; Gabelloni, D.; Martini, A.; Natalicchio, A. Crowdsourcing: A review and suggestions for future research. Int. J. Manag. Rev. 2018, 20, 343-363. [CrossRef]

35. Natalicchio, A.; Petruzzelli, A.M.; Garavelli, A.C. Innovation problems and search for solutions in crowdsourcing platforms-A simulation approach. Technovation 2017, 64, 28-42. [CrossRef]

36. Jespersen, K.R. Crowdsourcing design decisions for optimal integration into the company innovation system. Decis. Support Syst. 2018, 115, 52-63. [CrossRef]

37. Gupta, A.K.; Smith, K.G.; Shalley, C.E. The interplay between exploration and exploitation. Acad. Manag. J. 2006, 49, 693-706. [CrossRef] 
38. Cohen, B.; Almirall, E.; Chesbrough, H. The City as a Lab: Open Innovation Meets the Collaborative Economy. Calif. Manag. Rev. 2016, 59, 5-13. [CrossRef]

39. Poetz, M.K.; Schreier, M. The value of crowdsourcing: Can users really compete with professionals in generating new product ideas? J. Prod. Innov. Manag. 2012, 29, 245-256. [CrossRef]

40. Zheng, H.; Li, D.; Hou, W. Task Design, Motivation and Participation in Crowdsourcing. Int. J. Electron. Commer. 2011, 15, 57-88. [CrossRef]

41. Oguz, A.A. Motivations and solution appropriateness in crowdsourcing challenges for innovation. Res. Policy 2019, 48. [CrossRef]

42. Vignieri, V. Crowdsourcing as a mode of open innovation: Exploring drivers of success of a multisided platform through system dynamics modelling. Syst. Res. Behav. Sci. 2020, 38, 108-124. [CrossRef]

43. Zhao, Z. Idea Crowdsourcing for Innovation: Fundamentals and Recommendations. Manag. Datasci. 2009, 3. [CrossRef]

44. Taherdoost, H. Determining Sample Size; How to Calculate Survey Sample Size. Int. J. Econ. Manag. Syst. 2017, 2, 237-239. Available online: http:/ / ssrn.com/abstract=3224205 (accessed on 12 May 2021).

45. Kowal, J. Statystyka opisowa w zarzadzaniu. In Zarzadzanie Przedsiębiorcze; Knecht, Z., Ed.; WSZE: Wrocław, Poland, 2011.

46. Abdi, H. The Kendall Rank Correlation Coefficient. In Encyclopedia of Measurement and Statistics; Salkind, N., Ed.; SAGE Publications: Thousand Oaks, CA, USA, 2007.

47. Skotarczak, E.; Dobek, A.; Moliński, K. Comparison of some correlation measures for continuous and categorical data. Biom. Lett. 2019, 56, 253-261. [CrossRef]

48. Barczak, A.; Dembińska, I.; Marzantowicz, Ł.; Nowicka, K.; Szopik-Depczyńska, K.; Rostkowski, T. The Impact of Unpredictable Factors on the Uncertainty's Structure in the Management of Logistics Processes. Eur. Res. Stud. J. 2020, 23, 186-200. [CrossRef]

49. Newcombe, R.G. Two-sided confidence intervals for the single proportion: Comparison of seven methods. Stat. Med. 1998, 17, 857-872. [CrossRef]

50. Brown, L.D.; Cai, T.T.; Dasgupta, A. Interval estimation for a binomial proportion. Stat. Sci. 2001, 16, 101-133. [CrossRef]

51. Murtagh, F.; Legendre, P. Ward's Hierarchical Clustering Method: Clustering Criterion and Agglomerative Algorithm. J. Classif. 2014, 31, 274-295. [CrossRef]

52. Großwendt, A.; Röglin, H.; Schmidt, M. Analysis of Ward's Method. In Proceedings of the 2019 Annual ACM-SIAM Symposium on Discrete Algorithms (SODA), San Francisco, CA, USA, 6-9 January 2019. [CrossRef]

53. Bonald, T. Hierarchical Clustering. January 2019. Available online: http://perso.telecom-paristech.fr/bonald/documents/ hierarchy.pdf (accessed on 19 August 2021).

54. Eszergár-Kiss, D.; Caesar, B. Definition of user groups applying Ward's method. Transp. Res. Procedia 2017, 22, 25-34. [CrossRef]

55. Kearney, M.W. Cramer's V. In Sage Encyclopedia of Communication. Research Methods; Allen, M.R., Ed.; SAGE: Thousand Oaks, CA, USA, 2017. [CrossRef]

56. Huberman, B.A.; Romero, D.M.; Wu, F. Crowdsourcing, attention and productivity. J. Inf. Sci. 2009, 35, 758-765. [CrossRef]

57. Kleeman, F.; Voss, G.G.; Rieder, K. Un(der)paid innovators: The commercial utilization of consumer work through crowdsourcing. Sci. Technol. Innov. Stud. 2008, 4, 5-26.

58. Chanal, V.; Caron-Fasan, M.L. How to Invent a New Business Model Based on Crowdsourcing: The Crowdspirit Case. In Proceedings of the 17ième Conférence Internationale de Management Stratégique (AIMS), Nice, France, $28-31$ May 2008.

59. Schenk, E.; Guittard, C. Crowdsourcing: What Can Be Outsourced to the Crowd, and Why? Technical Report. 2009. Available online: http:/ / halshs.archives-ouvertes.fr/halshs-00439256/ (accessed on 10 September 2020).

60. Fernandez-Blanco, A.; Villanueva-Balsera, J.; Rodriguez-Montequin, V.; Moran-Palacios, H. Key factors for project crowdfunding success: An empirical study. Sustainability 2020, 12, 599. [CrossRef]

61. Walter, T.; Back, A. Towards Measuring Crowdsourcing Success: An Empirical Study on Effects of External Factors in Online Idea Contest. In Proceedings of the 6th Mediterranean Conference on Information Systems (MCIS 2011), Limassol, Cyprus, 3-5 September 2011.

62. Callaghan, C.M. The 'death of innovation' paradox, R\&D and the scientific potential of crowdsourcing. Afr. J. Sci. Technol. Innov. Dev. 2020, 12, 141-150. [CrossRef]

63. Guittard, C.; Schenk, E.; Burger-Helmchen, T. Crowdsourcing and the Evolution of a Business Ecosystem. In Advances in Crowdsourcing; Garrigos-Simon, F.J., Gil-Pechuán, I., Estelles-Miguel, S., Eds.; Springer: Berlin/Heidelberg, Germany, 2015.

64. Gonzalez Cabral, A.C.; Appelt, S.; Hanappi, T. Corporate Effective Tax Rates for RED: The Case of Expenditure-Based RED Tax Incentives; OECD Taxation Working Papers 54; OECD: Paris, France, 2020. [CrossRef]

65. Jiao, Y.; Wu, Y.; Lu, S. The role of crowdsourcing in product design: The moderating effect of user expertise and network connectivity. Technol. Soc. 2021, 64, 101496. [CrossRef]

66. Cummings, J.L.; Bing-Sheng, T. Transferring R\&D knowledge: The key factors affecting knowledge transfer success. J. Eng. Technol. Manag. 2003, 20, 39-68. [CrossRef]

67. Pollok, P.; Lüttgens, D.; Piller, F.T. Attracting solutions in crowdsourcing contests: The role of knowledge distance, identity disclosure, and seeker status. Res. Policy 2019, 48, 98-114. [CrossRef]

68. Niu, X.; Qin, S.; Zhang, H.; Wang, M.; Wong, R. Exploring product design quality control and assurance under both traditional and crowdsourcing-based design environments. Adv. Mech. Eng. 2018, 10, 1-23. [CrossRef] 